\title{
The Combination of Atorvastatin With Silymarin Enhances Hypolipidemic, Antioxidant and Anti-Inflammatory Effects in a Rat Model of Metabolic Syndrome
}

\author{
Irena MARKOVÁ ${ }^{1}$, Hana MALÍNSKÁ ${ }^{1}$, Martina HÜTTL ${ }^{1}$, Denisa MIKLÁNKOVÁ ${ }^{1}$, Olena \\ OLIYARNYK ${ }^{1}$, Martin PORUBA ${ }^{2}$, Zuzana RÁCOVÁ ${ }^{2}$, Ludmila KAZDOVÁ ${ }^{1}$, Rostislav \\ VEČEŘA ${ }^{2}$
}

${ }^{1}$ Centre for Experimental Medicine, Institute for Clinical and Experimental Medicine, Prague, Czech Republic, ${ }^{2}$ Department of Pharmacology, Faculty of Medicine and Dentistry, Palacky University Olomouc, Olomouc, Czech Republic

Received October 15, 2020

Accepted November 18, 2020

Epub Ahead of Print January 14, 2021

\section{Summary}

Hypolipidemic and cardioprotective effects of statins can be associated with the development of myopathies and new-onset type 2 diabetes. These adverse effects may be related to increased oxidative stress. The plant extract silymarin (SM) is known for its antioxidant and anti-inflammatory actions. We tested the hypothesis that the combination of atorvastatin (ATV) with SM could improve therapy efficacy and eliminate some negative effects of statin on hypertriglyceridemia-induced metabolic disorders. Hereditary hypertriglyceridemic rats were fed a standard diet for four weeks without supplementation; supplemented with ATV ( $5 \mathrm{mg} / \mathrm{kg}$ b. wt./day) or a combination of ATV with $1 \%$ micronized SM (ATV+SM). ATV treatment elevated plasma levels of HDL-cholesterol $(p<0.01)$, glucose and insulin and decreased triglycerides $(p<0.001)$. The combination of ATV+SM led to a significant reduction in insulin, an improvement of glucose tolerance, and the hypolipidemic effect was enhanced compared to ATV alone. Furthermore, ATV supplementation increased skeletal muscle triglycerides but its combination with SM decreased triglycerides accumulation in the muscle $(p<0.05)$ and the liver $(p<0.01)$. In the liver, ATV+SM treatment increased the activities of antioxidant enzymes, glutathione and reduced lipid peroxidation $(p<0.001)$. The combined administration of ATV with SM potentiated the hypolipidemic effect, reduced ectopic lipid accumulation, improved glucose metabolism, and increased antioxidant and anti-inflammatory actions. Our results show that SM increased the effectiveness of statin therapy in a hypertriglyceridemic rat model of metabolic syndrome.

\section{Key words}

Atorvastatin - Silymarin - Metabolic syndrome - Lipids • Oxidative stress

\section{Corresponding author}

I. Marková, Centre for Experimental Medicine, Institute for Clinical and Experimental Medicine, Vídeňská 1958/9, Prague 4, 140 21, Czech Republic. E-mail: irena.markova@ikem.cz

\section{Introduction}

Dyslipidemia increases the risk of the development of metabolic syndrome, cardiovascular disease (CVD) and type 2 diabetes mellitus. Statins, inhibitors of 3-hydroxy-3-methylglutaryl-coenzyme A (HMG-CoA) reductase, are frequently used drugs for the treatment of hypercholesterolemia, and their benefits for the treatment of CVD are widely accepted (Mihos et al. 2014, Silverman et al. 2016). Although the safety of statins has been documented and statins are well tolerated, some studies have revealed adverse effects of statin therapy on an increased risk of new-onset type 2 diabetes mellitus (mainly in prediabetic individuals) or hepatotoxicity (Aiman et al. 2014, Mach et al. 2018, Ward et al. 2019). The most severe adverse effects are statin associated myopathies, which can lead to nonadherence to statin therapy (Ward et al. 2019). Despite infrequent, these side effects represent serious drawbacks 
in otherwise very beneficial use of statins especially when numerous population is exposed to these drugs. Till now, mechanisms of these side effects are not well understood, but it has been shown that an impairment of mitochondrial function due to statin-induced decreased synthesis of coenzyme Q10 and increased oxidative stress could play an important role (Bouitbir et al. 2020).

Current research efforts are focused on a search for additional substances that would alleviate statininduced adverse effects or positively influence hypolipidemic therapy. Silymarin (SM) is a compound, which, due its properties could modify described untoward effects of statins or improve the effectiveness of statin therapy. SM is an extract from milk thistle seeds (Silybum marianum) containing a mixture of flavonolignans $(60-85 \%)$, fatty acids $(20-35 \%)$ and polyphenolic and flavonoid compounds, which exhibit potent antioxidant, anti-inflammatory and regenerative properties (Surai 2015). SM and its major effective component silybin, are mostly used for the treatment of liver disorders (Neha et al. 2016). In a previous study, we found that SM inhibited intestinal cholesterol absorption, decreased plasma cholesterol concentrations and increased HDL-cholesterol levels in rats fed high cholesterol diet (Sobolova et al. 2006). We also demonstrated the beneficial effect of SM on lipid disorders and oxidative stress in the model of dyslipidemia and metabolic syndrome. A diet with $1 \%$ SM supplement decreased plasma VLDL-cholesterol levels, increased levels of glutathione (GSH) in blood and liver and the activity of superoxide dismutase (SOD), and reduced the production of lipid peroxides in the liver (Skottova et al. 2004). The therapeutic efficacy of SM is influenced by its low solubility in water, and rapid elimination, resulting in low bioavailability. Micronized form of SM provides significantly increased bioavailability compared to the standard form of SM (Javed et al. 2011). Recently, we demonstrated that micronized SM provided more pronounced effects than the standard form. Micronized forms of SM or silybin caused the highest increase of HDL-cholesterol levels and most significantly decreased glycemia and insulinemia in the animal model of metabolic syndrome compared to standard forms (Poruba et al. 2015a, Poruba et al. 2015b).

In the current study, we aimed to investigate whether a combination of SM and atorvastatin (ATV), one of the most commonly prescribed statins (Salami et al. 2017), can favorably affect already-developed metabolic disorders. Using a model of genetically-fixed hypertriglyceridemia associated with metabolic syndrome and prediabetes, we tested the hypothesis that the addition of SM to ATV can have a beneficial effect on dyslipidemia and eliminate some negative effects of statin treatment. Non-obese hereditary hypertriglyceridemic rats (HHTg) were used, which exhibit dyslipidemia, liver steatosis, insulin resistance, impaired glucose tolerance and increased oxidative stress (Vrana and Kazdova 1990, Zicha et al. 2006, Malinska et al. 2018). The therapeutic effects of ATV with SM have not yet been tested and evidence on interactions of SM with ATV are lacking.

\section{Materials and Methods}

\section{Animals and diet}

The HHTg rats were provided by the Institute for Clinical and Experimental Medicine (Prague, Czech Republic). All experiments were performed in agreement with the Animal Protection Law of the Czech Republic (359/2012), which is in compliance with the European Community Council recommendations for the use of laboratory animals $(86 / 609 / \mathrm{ECC})$ and approved by the Ethics Committee of the Institute for Clinical and Experimental Medicine, Prague (Protocol Number: 28/2016).

The rats were maintained in a 12-h light/12-h dark cycle room at a temperature of $22-25^{\circ} \mathrm{C}$, and allowed free access to food and water. Five-month-old HHTg rat males were randomly divided into three experimental groups of eight animals. The control group (control) was fed a standard laboratory diet (SD), the atorvastatin group (ATV) was fed a SD supplemented with ATV (Mylan, UK) at a dose of $5 \mathrm{mg} / \mathrm{kg} \mathrm{b}$. wt./day, and the atorvastatin and silymarin group (ATV+SM) was fed a SD with ATV and micronized $\mathrm{SM}$ ( $1 \%$ of micronized $\mathrm{SM}$ in SD, supplied from Favea, Koprivnice, Czech Republic) for four weeks. The standardized micronized extract of SM with declared purity $80 \%$ was used. The total content of silybin diastereomers (31.4 $\pm 0.9 \%$ ) was determined using HPLC with UV detection. At the end of the study, animals were sacrificed by decapitation in a postprandial state, and blood plasma and tissue samples were taken for incubation analysis or stored at $-80^{\circ} \mathrm{C}$ for subsequent analysis.

\section{Biochemical analysis in plasma}

Plasma levels of triglycerides (TG), nonesterified fatty acids (NEFA), glucose and total cholesterol were measured using commercially available 
kits (Erba Lachema, Brno, Czech Republic). Creatine kinase enzyme activity was determined spectrophotometrically by routine clinical biochemistry methods with a commercial kit (Roche Diagnostics, Mannheim, Germany). Plasma insulin and monocyte chemoattractant protein 1 (MCP-1) concentrations were determined using a Rat Insulin ELISA kit (Mercodia AB, Uppsala, Sweden) and a Rat MCP-1 Instant ELISA kit (eBioscience, Vienna, Austria), respectively. Plasma interleukin 6 (IL-6) and high sensitivity C-reactive protein (hsCRP) were also measured using rat ELISA kits (MyBioSource, San Diego, CA, USA and BioVendor, Brno, Czech Republic), respectively.

For the oral glucose tolerance test (OGTT), blood glucose was determined after a glucose load (3 $\mathrm{g}$ of glucose $/ \mathrm{kg}$ b. wt.) administered intragastrically after overnight fasting. Glucose concentrations were determined by analyzing blood samples collected from the tail vein before the glucose load at $0 \mathrm{~min}$ and 30,60 and $120 \mathrm{~min}$ after glucose loading. The area under the glycemic curve $\left(\mathrm{AUC}_{0-120 \mathrm{~min}}\right)$ was calculated over a 120 -min period.

\section{Tissue triglyceride and cholesterol measurements}

For TG and cholesterol determination in liver and TG in muscle and kidney, tissue samples were powered under liquid $\mathrm{N}_{2}$ and extracted in chloroform/methanol. Than, a solution of $2 \%$ potassium dihydrogenphosphate was added, the mixture was centrifuged, the organic phase removed, and evaporated under $\mathrm{N}_{2}$. The resulting pellet was dissolved in isopropyl alcohol, and TG and cholesterol content was measured by an enzymatic assay (Erba-Lachema, Brno, Czech Republic).

\section{Tissue insulin sensitivity}

For ex vivo measurements of the insulinstimulated incorporation of glucose into glycogen in muscle or lipids in visceral adipose tissue, the diaphragm or distal parts of epididymal adipose tissue were rapidly dissected and immediately incubated for $2 \mathrm{~h}$ in KrebsRinger bicarbonate buffer ( $\mathrm{pH} 7.4$ ) containing $0.1 \mu \mathrm{Ci} / \mathrm{ml}$ of ${ }^{14} \mathrm{C}-\mathrm{U}$ glucose, $5.5 \mathrm{mM}$ unlabeled glucose and $2.5 \mathrm{mg} / \mathrm{ml}$ of bovine serum albumin (Sigma-Aldrich, St. Louis, MO, USA) without or with $250 \mu \mathrm{U} / \mathrm{ml}$ of insulin at $37^{\circ} \mathrm{C}$. Glycogen and lipids were extracted, and the basal and insulin-stimulated incorporation of glucose into glycogen or lipids were determined as previously described (Qi et al. 2002). Radioactivity was measured by scintillation counting.

\section{Oxidative stress parameters}

The concentration of GSH was determined by HPLC with fluorescent detection using a HPLC diagnostic kit (Chromsystems, Gräfelfing, Germany).

Antioxidant enzyme activities of SOD, glutathione reductase (GR), glutathione peroxidase (GPx) and glutathione transferase (GST) were measured using commercially available kits (Cayman Chemicals; Ann Arbor, MI, USA). Catalase (CAT) activity was determined based on the ability of $\mathrm{H}_{2} \mathrm{O}_{2}$ to form a color complex with ammonium molybdate and detected spectrophotometrically. Parameter of lipid peroxidation, thiobarbituric acid reactive substances (TBARS), were determined by a spectrophotometric method described previously (Malinska et al. 2010).

\section{Gene expression assays}

Total mRNA was isolated from liver tissue using an RNeasy Plus Mini Kit (Qiagen; Valencia, CA, USA). For the synthesis of cDNA, a Transcriptor High Fidelity cDNA synthesis kit (F. Hoffmann-La Roche AG, Basel, Switzerland) was used. A real-time PCR analysis was performed on 1536-well plates using an Echo 550 acoustic liquid handler (Labcy, Dublin, Ireland) and a LightCycler 1536 instrument (Hoffmann-La Roche AG, Basel, Switzerland). The results were calculated using the $\Delta \Delta \mathrm{Ct}$ method and all results were normalized and related to the Hprt1 gene. TaqMan probes for Hmgcr, Abcg5, Abcg8, Srebf1, Srebf2 and Hprt1 were obtained from Life Technologies (Thermo Fisher Scientific, Waltham, MA, USA).

\section{Statistical analysis}

Data were expressed as mean \pm standard error of the mean (SEM). Data obtained in this study were analyzed by StatSoft ${ }^{\circledR}$ Statistica software (ver. 10, Statsoft CZ; Prague, Czech Republic). All statistical analysis were performed by one-way ANOVA because all data had a normal distribution. For detailed comparisons, post hoc Bonferroni tests were used to avoid false positive results. Statistical significance was defined as $\mathrm{p}<0.05$.

\section{Results}

The combination of ATV and SM ameliorated dyslipidemia and ATV-induced disorders of glucose homeostasis

Neither ATV treatment alone nor the combination of ATV+SM affected food intake (data not shown) or body weight (Table 1). The relative weight of 
epididymal fat was not influenced by ATV treatment alone. However, compared to ATV-treated rats, the combined administration of ATV+SM decreased relative weight $(-17 \% ; \mathrm{p}<0.05)$. ATV significantly increased plasma levels of HDL-cholesterol $(+20 \%$; $<0.01)$ and decreased levels of TG $(-46 \% ; \mathrm{p}<0.001)$. The combination of ATV+SM further decreased TG plasma concentrations. In contrast, plasma concentrations of total cholesterol were not affected in this experiment. Treatment with ATV elevated glycemia and insulinemia, but the combination of ATV+SM reduced plasma insulin and slightly improved glucose tolerance measured by OGTT compared to ATV-treated group. During the study, no negative effects of statin therapy on skeletal muscles were observed, and creatine kinase activity did not differ among experimental groups (Table 1).

Table 1. Metabolic effects of ATV and ATV+SM treatment.

\begin{tabular}{|c|c|c|c|c|c|}
\hline & Control & ATV & $\mathbf{p}^{1}$ & $\mathbf{A T V}+\mathbf{S M}$ & $\mathbf{p}^{2}$ \\
\hline Body weight (g) & $409 \pm 7$ & $420 \pm 7$ & NS & $416 \pm 8$ & NS \\
\hline $\begin{array}{l}\text { Relative weight of epididymal } \\
\text { fat (g/100 g body weight) }\end{array}$ & $1.50 \pm 0.09$ & $1.74 \pm 0.08$ & NS & $1.44 \pm 0.08$ & $<0.05$ \\
\hline$T G(\mathrm{mmol} / \mathrm{l})$ & $4.29 \pm 0.21$ & $2.30 \pm 0.11$ & $<0.001$ & $1.51 \pm 0.09$ & $<0.001$ \\
\hline NEFA $(\mathrm{mmol} / \mathrm{l})$ & $0.69 \pm 0.05$ & $0.79 \pm 0.05$ & NS & $0.63 \pm 0.03$ & NS \\
\hline Cholesterol (mmol/l) & $1.77 \pm 0.04$ & $1.85 \pm 0.02$ & NS & $1.85 \pm 0.05$ & NS \\
\hline HDL-cholesterol (mmol/l) & $1.01 \pm 0.04$ & $1.21 \pm 0.03$ & $<0.01$ & $1.24 \pm 0.05$ & NS \\
\hline Insulin $($ nmol/l) & $0.21 \pm 0.03$ & $0.32 \pm 0.03$ & $<0.05$ & $0.16 \pm 0.02$ & $<0.01$ \\
\hline Non-fasting glucose (mmol/l) & $8.86 \pm 0.17$ & $9.50 \pm 0.16$ & $<0.05$ & $9.80 \pm 0.13$ & NS \\
\hline$A U C_{0-120 \min }(\mathrm{mmol} / \mathrm{l} / 2 \mathrm{~h})$ & $729 \pm 17$ & $739 \pm 7$ & NS & $678 \pm 18$ & $<0.05$ \\
\hline Creatine kinase ( $\mu$ kat/l) & $3.85 \pm 0.28$ & $3.11 \pm 0.32$ & NS & $3.48 \pm 0.25$ & NS \\
\hline
\end{tabular}

Data are expressed as mean \pm SEM; $n=8 /$ group. $p^{1}$ denotes significant difference between the control vs. ATV treated groups, $\mathrm{p}^{2}$ denotes significant difference between ATV vs. ATV+SM treated groups, NS - not significant difference. ATV - experimental group of rats treated with atorvastatin, ATV+SM - experimental group of rats treated with atorvastatin and silymarin, TG - triglycerides, NEFA nonesterified fatty acids, $\mathrm{AUC}_{0-120 \mathrm{~min}}$ - the area under the curve during the oral glucose tolerance test.

The combination of ATV and SM ameliorated ATV-induced ectopic lipid accumulation

Concentrations of lipids were analyzed in the liver, skeletal muscle (Musculus gastrocnemius) and kidney (Table 2). ATV treatment did not affect ectopic TG accumulation in the liver but increased TG amount in skeletal muscle and hepatic cholesterol. The combination of ATV with SM reduced these adverse effects. The amount of TG in the liver was reduced by $30 \%(p<0.01)$, cholesterol by $11 \%(\mathrm{p}<0.01)$, and skeletal muscle TG by $29 \%(\mathrm{p}<0.05)$ after ATV+SM treatment compared to ATV treatment alone. TG accumulation in the kidney was not affected by ATV alone or the combination of $\mathrm{ATV}+\mathrm{SM}$.

Table 2. Effect of ATV and ATV+SM treatment on triglycerides accumulation in tissues.

\begin{tabular}{lccccc}
\hline & Control & ATV & $\mathbf{p}^{\mathbf{1}}$ & ATV+SM & $\mathbf{p}^{\mathbf{2}}$ \\
\hline Liver TG $(\mu \mathrm{mol} / \mathrm{g})$ & $9.44 \pm 0.62$ & $10.89 \pm 0.76$ & $\mathrm{NS}$ & $7.59 \pm 0.47$ & $<0.01$ \\
Liver cholesterol $(\mu \mathrm{mol} / \mathrm{g})$ & $13.39 \pm 0.26$ & $14.56 \pm 0.21$ & $<0.05$ & $12.94 \pm 0.39$ & $<0.01$ \\
Muscle TG $(\mu \mathrm{mol} / \mathrm{g})$ & $3.52 \pm 0.44$ & $5.74 \pm 0.49$ & $<0.01$ & $4.05 \pm 0.29$ & $<0.05$ \\
Kidney TG $(\mu \mathrm{mol} / \mathrm{g})$ & $5.68 \pm 0.57$ & $5.84 \pm 0.40$ & $\mathrm{NS}$ & $5.84 \pm 0.35$ & NS \\
\hline
\end{tabular}

Data are expressed as mean $\pm S E M ; n=8 /$ group. $p^{1}$ denotes significant difference between the control vs. ATV treated groups, $\mathrm{p}^{2}$ denotes significant difference between ATV vs. ATV+SM treated groups, NS - not significant difference, ATV - experimental group of rats treated with atorvastatin, ATV+SM - experimental group of rats treated with atorvastatin and silymarin, TG - triglycerides. 
The combination of ATV and SM increased adipose tissue insulin sensitivity

Figure 1 shows the basal and insulin stimulated glucose incorporation into lipids of epididymal adipose tissue and into muscle glycogen. While ATV treatment did not affect basal or insulin-stimulated lipogenesis, combined ATV+SM intervention increased the insulinstimulated incorporation of ${ }^{14} \mathrm{C}-\mathrm{U}$ glucose into lipids of adipose tissue (Fig. 1A).

As shown in Figure 1B, neither ATV alone nor the combination of ATV+SM affected the basal or insulin-stimulated incorporation of ${ }^{14} \mathrm{C}-\mathrm{U}$ glucose into muscle glycogen, indicating no changes in muscle tissue insulin sensitivity.

The combination of ATV and SM ameliorated plasma inflammation parameters

As shown in Table 3, the plasma concentration of hsCRP was increased after ATV treatment, but the combination of ATV+SM suppressed this negative effect. Also, the level of proinflammatory IL-6 was favorably influenced by the combination of ATV+SM, while the concentration of MCP-1 was not affected by any treatment.
A

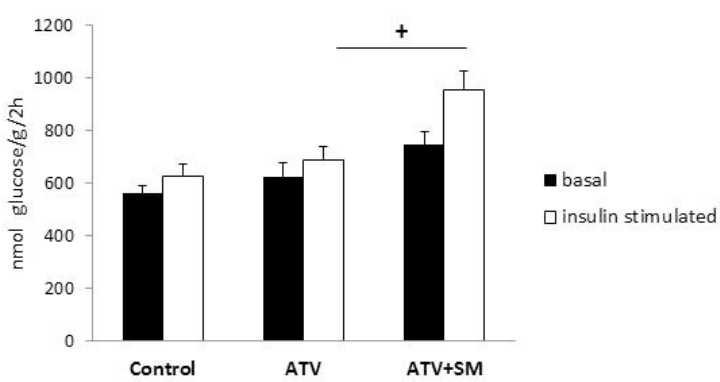

B

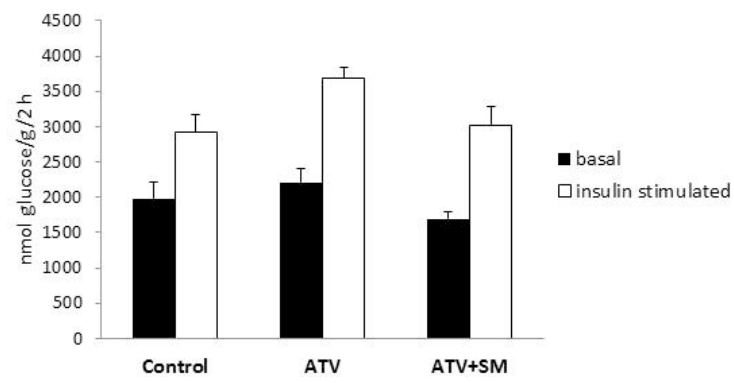

Fig. 1. Effect of ATV and ATV+SM treatment on visceral adipose tissue (A) and muscle (B) sensitivity to insulin action. Data are expressed as mean \pm SEM; $n=8 /$ group. ${ }^{+} p<0.05$ denotes significant difference between ATV vs. ATV+SM treated groups. ATV - experimental group of rats treated with atorvastatin, ATV+SM - experimental group of rats treated with atorvastatin and silymarin.

Table 3. Effect of ATV and ATV+SM treatment on plasma inflammation parameters.

\begin{tabular}{lccccc}
\hline & Control & ATV & $\mathbf{p}^{\mathbf{1}}$ & ATV+SM & $\mathbf{p}^{\mathbf{2}}$ \\
\hline$h s C R P(\mathrm{mg} / \mathrm{ml})$ & $0.83 \pm 0.05$ & $1.07 \pm 0.06$ & $<0.01$ & $0.87 \pm 0.04$ & $<0.05$ \\
$M C P-1(\mathrm{pg} / \mathrm{ml})$ & $3863 \pm 308$ & $4352 \pm 342$ & $\mathrm{NS}$ & $4745 \pm 314$ & $\mathrm{NS}$ \\
$I L-6(\mathrm{pg} / \mathrm{ml})$ & $97.4 \pm 4.3$ & $93.7 \pm 6.1$ & $\mathrm{NS}$ & $72.8 \pm 3.9$ & $<0.05$ \\
\hline
\end{tabular}

Data are expressed as mean $\pm \mathrm{SEM} ; \mathrm{n}=8$ /group. $\mathrm{p}^{1}$ denotes significant difference between the control vs. ATV treated groups, $\mathrm{p}^{2}$ denotes significant difference between ATV vs. ATV+SM treated groups, NS - not significant difference. ATV - experimental group of rats treated with atorvastatin, ATV+SM - experimental group of rats treated with atorvastatin and silymarin, hsCRP - high sensitivity C-reactive protein, MCP-1 - monocyte chemoattractant protein 1, IL-6 - interleukin 6.

Relative mRNA expression of genes important in cholesterol and lipid metabolism in the liver

ATV treatment increased the relative mRNA expression of Hmgcr (Fig. 2A) and cholesterol transporters G5 and G8 ( $\mathrm{Abcg} 5$ and $\mathrm{Abcg} 8$ ) compared to the control group (Fig. 2B), while the combination of ATV $+\mathrm{SM}$ further enhanced Abcg5 mRNA expression. On the other hand, hepatic mRNA expression of the transcription factor Srebf-1 was decreased after ATV alone, and Srebf-2 was decreased after $\mathrm{ATV}+\mathrm{SM}$ treatment, as shown in Figure $2 \mathrm{C}$.
The combination of ATV and SM improved oxidative stress in the liver

As shown in Table 4, ATV treatment significantly affected only activity of GST. Liver concentrations of GSH as well as the activities of antioxidant enzymes SOD and CAT were significantly increased in the HHTg rats treated with the combination of ATV and SM when compared to ATV treated rats. Increased antioxidant enzyme activities were associated with amelioration of oxidative stress as the concentrations of lipoperoxidation products measured as TBARS were reduced after ATV+SM treatment vs. ATV treated rats. 
A

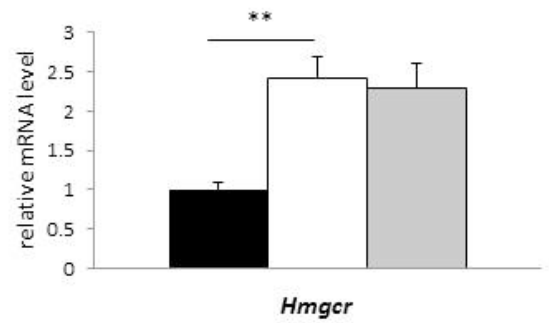

B

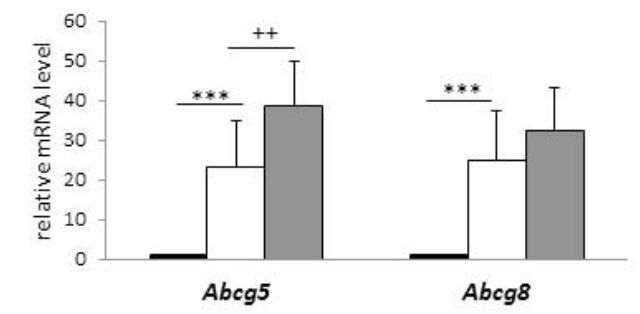

c

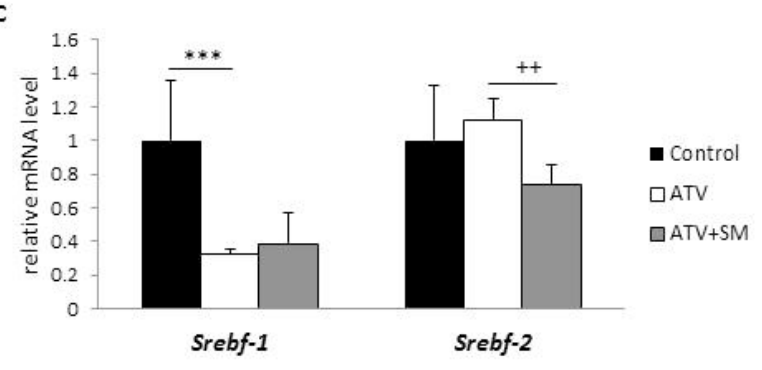

Fig. 2. Effect of $A T V$ and $A T V+S M$ treatment on the relative mRNA expression of $\mathrm{Hmgcr}(\mathbf{A}), A b c g 5$ and $A b c g 8$ (B) and Srebf-1 and Srebf-2 (C) in the liver of HHTg rats. Data are expressed as mean \pm SEM; $n=8 /$ group. $* * \mathrm{p}<0.01$ and $* * * p<0.001$ denotes significant difference between the control vs. ATV treated groups, and ${ }^{++} p<0.01$ denotes significant difference between ATV vs. ATV+SM treated groups. ATV experimental group of rats treated with atorvastatin, ATV+SM experimental group of rats treated with atorvastatin and silymarin. Hmgcr - 3-hydroxy-3-methylglutaryl-CoA reductase, Abcg5 and Abcg8 - genes for ATP-binding cassette (ABC) cholesterol transporters G5 and G8, Srebf-1 and Srebf-2 - genes for sterol regulatory element binding transcription factor 1 and 2 .

\section{Discussion}

Statins are the standard therapy for management of hypercholesterolemia. They are very effective drugs for prevention of CVD and are one of the most prescribed medications in the world. Nevertheless, side effects of treatment with statins were described including increased risk of new-onset type 2 diabetes mellitus and myopathies. Adverse effects may affect up to $10-15 \%$ of patients (Ward et al. 2019). One possibility to reduce statin-induced adverse events includes using combination of statins with the nutraceuticals which may favorably

Table 4. Parameters of oxidative stress in the liver of HHTg rats after ATV and ATV+SM treatment.

\begin{tabular}{|c|c|c|c|c|c|}
\hline & Control & ATV & $\mathrm{p}^{1}$ & $\mathbf{A T V}+\mathbf{S M}$ & $\mathbf{p}^{2}$ \\
\hline SOD (U/mg protein) & $0.101 \pm 0.003$ & $0.095 \pm 0.005$ & NS & $0.120 \pm 0.006$ & $<0.01$ \\
\hline $\begin{array}{l}\mathrm{CAT}\left(\mu \mathrm{MH} \mathrm{H}_{2} \mathrm{O}_{2} \mathrm{~min} / \mathrm{mg}\right. \\
\text { protein })\end{array}$ & $1385 \pm 136$ & $1250 \pm 106$ & NS & $2015 \pm 40$ & $<0.001$ \\
\hline $\begin{array}{l}\text { GR (nM NADPH/min/mg } \\
\text { protein) }\end{array}$ & $141 \pm 9$ & $149 \pm 11$ & NS & $162 \pm 13$ & NS \\
\hline $\begin{array}{l}\text { GPx ( } \mu M N A D P H / \mathrm{min} / \mathrm{mg} \\
\text { protein) }\end{array}$ & $284 \pm 13$ & $303 \pm 18$ & NS & $299 \pm 10$ & NS \\
\hline $\begin{array}{l}\text { GST (nM CDNB/min } / \mathrm{mg} \\
\text { protein) }\end{array}$ & $128 \pm 8$ & $174 \pm 14$ & $<0.05$ & $194 \pm 12$ & NS \\
\hline GSH ( $\mu \mathrm{mol} / m g$ protein) & $69.00 \pm 1.54$ & $73.64 \pm 1.44$ & NS & $80.26 \pm 1.68$ & $<0.05$ \\
\hline TBARS (nM/mg protein) & $1.55 \pm 0.12$ & $1.71 \pm 0.14$ & NS & $1.02 \pm 0.05$ & $<0.001$ \\
\hline
\end{tabular}

Data are expressed as mean $\pm S E M ; n=8 /$ group. $p^{1}$ denotes significant difference between the control vs. ATV treated groups, $\mathrm{p}^{2}$ denotes significant difference between ATV vs. ATV+SM treated groups, NS - not significant difference. ATV - experimental group of rats treated with atorvastatin, ATV+SM - experimental group of rats treated with atorvastatin and silymarin, GSH - reduced form of glutathione, SOD - superoxide dismutase, CAT - catalase, GR - glutathione reductase, GPx - glutathione peroxidase, GST - glutathione transferase, TBARS - thiobarbituric acid reactive substances.

affect metabolic disorders (Banach et al. 2018). The plant extract SM is a natural compound, which due to its antioxidant and anti-inflammatory properties could alleviate the unfavorable effects of statins. In the current study, we provide new findings showing that the addition of SM to ATV treatment reduced adverse effects of statin therapy on a number of metabolic parameters, and in some cases their combination proved to be much more effective than ATV treatment alone. We found that the combination of ATV with SM increased hypolipidemic 
action of ATV, decreased hepatic steatosis and ectopic deposition of lipids to the muscle, favorably influenced glucose homeostasis, insulin sensitivity of adipose tissue and reduced oxidative stress and inflammation.

We tested the effects of ATV treatment alone and in combination with SM on already developed metabolic disorders associated with genetically induced hypertriglyceridemia in the HHTg rat model. This unique strain of rats selected from Wistar rats, exhibits most of the symptoms of metabolic syndrome and thus represents a suitable model for the study of dyslipidemia, insulin resistance and prediabetes (Vrana and Kazdova 1990, Zicha et al. 2006). In the study, we used micronized form of SM whose bioavailability is higher than conventional forms of SM, thereby increasing its therapeutic potential (Di Costanzo and Angelico 2019).

After four weeks of ATV treatment, we found improved dyslipidemia in HHTg rats. We noticed markedly decreased plasma $\mathrm{TG}$ concentrations and increased levels of HDL-cholesterol, which suggest potentially anti-atherogenic effect of ATV. The combined ATV + SM administration further decreased plasma TG but had no additional effect on HDL-cholesterol levels. These data demonstrate that the addition of SM to statin therapy enhances TG lowering effect of ATV. The hypolipidemic effect of SM is in line with our previous findings demonstrating its positive effect on serum levels of TG in HHTg rats (Poruba et al. 2015a). Recently, Ebrahimpour-Koujan et al. reported similar results showing that SM supplementation led to a significant reduction in serum $\mathrm{TG}$ and total cholesterol, and an elevation of HDL-cholesterol levels (EbrahimpourKoujan et al. 2018).

An increased incidence of new-onset type 2 diabetes mellitus has been observed as a consequence of statin therapy. A meta-analysis of 13 randomized controlled trials reported a $9 \%$ higher risk of the development of diabetes mellitus in statin treated patients compared to patients treated with placebo or standard therapy (Sattar et al. 2010). Also, a meta-analysis of 20 observational studies showed that new-onset diabetes was higher in statin users than nonusers (Casula et al. 2017). On the other hand, in a clinical trial with type 2 diabetes mellitus patients, treatment with SM reduced serum levels of insulin and improved glycemic indices (Ebrahimpour-Koujan et al. 2018). In another study, long-term treatment with SM was effective in reducing insulin resistance and maintaining a better metabolic compensation of glucose metabolism in diabetic patients
(Velussi et al. 1997). In our study, we found that while administration of ATV alone increased plasma levels of glucose and insulin, the addition of SM to statin therapy ameliorated these adverse consequences as markedly reduced insulinemia and improved glucose tolerance. Our findings showed that SM can beneficially influence glucose homeostasis.

One of the most serious complications associated with hypertriglyceridemia and metabolic syndrome is increased lipid accumulation in non-adipose tissues. Ectopically stored lipids and their metabolites (diacylglycerols, ceramides, fatty acyl-CoA) in liver, heart, muscle and kidney lead to lipotoxicity which may result in hepatic steatosis, muscle insulin resistance, and increased risk of atherosclerosis (Stefan et al. 2005, Boren et al. 2013). Therefore, important results of our study in terms of the pathogenesis of organ complications in metabolic syndrome is finding that ATV-induced increased accumulation of cholesterol and TG in the liver and TG in skeletal muscle were reduced by adding SM to ATV therapy. Although the levels of TG in muscle decreased, muscle insulin sensitivity was unchanged after ATV + SM treatment. The transcription factor Nrf2 (nuclear factor erythroid 2-related factor 2) can play an important role in the mechanism responsible for $\mathrm{ATV}+\mathrm{SM}$ benefits on ectopic lipid accumulation in the liver, skeletal muscle, and related insulin resistance. Polyphenolic substances are important activators of Nrf2, which regulates more than 100 genes involved in regulating lipid metabolism, anti-oxidative, and antiinflammatory responses and enhances insulin signaling (Yu et al. 2012).

To search for the mechanisms responsible for the hypolipidemic effects mentioned above we focused on the hepatic mRNA expression of genes important in cholesterol and lipid metabolism. ATV treatment increased the relative mRNA expression of Hmgcr in the liver, and this could be attributed to the response to statin inhibition. Also, the mRNA expression of the Abcg5 and Abcg8 genes was markedly increased after ATV treatment, and the ATV+SM combination further increased Abcg5 mRNA expression. ABCG5/8 transporters play an important role in sterol absorption and excretion and represent an important elimination pathway for the cholesterol (Poruba et al. 2019). The increased mRNA expression of these transporters indicates higher cholesterol secretion from hepatocytes into the bile. Upregulation of Abcg5 and Abcg8 genes has been observed also in liver after pravastatin therapy (Kamisako 
and Ogawa 2004). Next we analysed transcription factors Srebf- 1 and Srebf-2 that regulate lipid homeostasis by controlling the expression of enzymes required for lipid synthesis. While Srebf-1 is involved especially in fatty acid synthesis in the liver and adipose tissue, Srebf-2 regulates genes of cholesterol metabolism, the most important being $\mathrm{Hmgcr}$ and LDL receptor. Srebf-2 is therefore an important regulatory checkpoint responsible for controlling intracellular cholesterol homeostasis (Eberle et al. 2004). In our study, the mRNA expression of Srebf-1 was markedly decreased after ATV treatment, while no change was observed in Srebf-2 mRNA. The combination of ATV+SM reduced Srebf-2 mRNA. There are many factors such as feedback mechanism, inflammatory cytokines, insulin resistance and hyperinsulinemia that could be involved in the regulation of Srebfs (Van Rooyen and Farrell 2011). Our results suggest that a significant decrease in insulinemia and IL-6 concentrations in animals fed a combination of ATV and SM could be involved in regulation of Srebf- 2 .

The role of chronic, low-grade inflammation in the pathogenesis of insulin resistance and other dyslipidemia-induced disorders is being increasingly recognized (Guo et al. 2016). Clinical observations have demonstrated that all components of metabolic syndrome, including insulin resistance, dyslipidemia and impaired glucose tolerance, correlate with serum C-reactive protein and oxidative stress levels (Devaraj et al. 2009). Our results showed that the combination therapy of ATV+SM reduced the concentrations of the inflammatory markers hsCRP and IL-6 in plasma. This effect could be mediated via the inhibition of the nuclear transcription factor kappa B (NF-kB) signaling pathway, which plays an essential role in inflammatory responses. Various plantderived polyphenols including SM can suppress NF-אB associated inflammatory pathways both in vitro and in vivo (Surai 2015, Gu et al. 2016). It has been shown in obese, insulin resistant mice that SM treatment significantly decreased pro-inflammatory cytokine levels of tumor necrosis factor $\alpha(\mathrm{TNF} \alpha)$ and IL-6 in the serum and liver (Guo et al. 2016). In addition, IL-6 is directly involved in the development of insulin resistance (Rehman et al. 2017). Therefore, the inhibitory effect of SM on NF- $\mathrm{KB}$ signaling could be an important mechanism in its anti-inflammatory efficacy (Surai 2015).

Oxidative stress is another important factor that contributes to the development of insulin resistance, and impairs the lipid profile and glucose tolerance
(Tangvarasittichai 2015). In addition, oxidative stress is involved in the development of organ complications such as NAFLD (non-alcoholic fatty liver disease). We therefore analyzed parameters of oxidative stress in the liver. While ATV in the liver almost did not affect the antioxidant system, the combination of $\mathrm{ATV}+\mathrm{SM}$ increased the activity of SOD, CAT and the concentration of GSH. Together with reduced TG accumulation, these changes led to a decrease in the formation of lipoperoxidation products, significantly improving hepatic oxidative stress. The antioxidant effects of SM are well known and may be a consequence of direct free radical scavenging, the reduced production of reactive oxygen substances in mitochondria, changes in cytochrome P450 enzyme activity, and increasing antioxidant defense via the nuclear transcription factor Nrf2 (Surai 2015, Gillessen and Schmidt 2020). Our results suggest that ATV in combination with SM can ameliorate oxidative stress and together with decreased inflammation can reduce the progression of metabolic syndrome to type 2 diabetes.

\section{Conclusions}

Our results show that the combined administration of ATV with SM potentiated the hypolipidemic effect, reduced ectopic lipid accumulation, increased antioxidant and anti-inflammatory actions, and positively influenced glucose homeostasis in hypertriglyceridemia-induced metabolic disorders. This strongly suggests that SM could increase the effectiveness of statin therapy, especially in individuals with metabolic syndrome and diabetes. These findings could also have implications for clinical science.

\section{Conflict of Interest}

There is no conflict of interest.

\section{Acknowledgements}

The study was supported by the Czech Science Foundation GACR, project number 17-08888-S and by the Ministry of Health of the Czech Republic under the conceptual development of research organizations programme (Institute for Clinical and Experimental Medicine - IKEM, IN 00023001). We wish to thank Jan Pitha for his extensive help with reviewing the manuscript and David Hardekopf for his extensive help with correcting the text. 


\section{Abbreviations}

Abcg5, Abcg8 - ATP-binding cassette cholesterol transporter G5and G8, ATV - atorvastatin, $\mathrm{AUC}_{0-120 \text { min }}$ the area under the curve during the oral glucose tolerance test, CAT - catalase, CVD - cardiovascular disease, GPx - glutathione peroxidase, GR - glutathione reductase, GSH - reduced form of glutathione, GST - glutathione transferase, HHTg - hereditary hypertriglyceridemic rat, HMG-CoA - 3-hydroxy-3-methylglutaryl-coenzyme A, Hmger - 3-hydroxy-3-methylglutaryl-coenzyme A reductase, hsCRP - high sensitivity C-reactive protein, IL-6 - interleukin 6, MCP-1 - monocyte chemoattractant protein 1 , NEFA - nonesterified fatty acids, NF- $\mathrm{B}$ nuclear factor kappa B, Nrf2 - nuclear factor erythroid 2related factor 2, SM - silymarin, SOD - superoxide dismutase, Srebf-1, Srebf-2 - sterol regulatory element binding transcription factor 1 and 2, TBARS thiobarbituric acid reactive substances, TG triglycerides, TNF $\alpha$ - tumor necrosis factor $\alpha$.

\section{References}

AIMAN U, NAJMI A, KHAN RA: Statin induced diabetes and its clinical implications. J Pharmacol Pharmacother 5: 181-185, 2014. https://doi.org/10.4103/0976-500X.136097

BANACH M, PATTI AM, GIGLIO RV, CICERO AFG, ATANASOV AG, BAJRAKTARI G, BRUCKERT E, DESCAMPS O, DJURIC DM, EZHOV M, FRAS Z, VON HAEHLING S, KATSIKI N, LANGLOIS M, LATKOVSKIS G, MANCINI GBJ, MIKHAILIDIS DP, MITCHENKO O, MORIARTY PM, MUNTNER P, ET AL.: The role of nutraceuticals in statin intolerant patients. J Am Coll Cardiol 72: 96-118, 2018. https://doi.org/10.1016/j.jacc.2018.04.040

BOREN J, TASKINEN MR, OLOFSSON SO, LEVIN M: Ectopic lipid storage and insulin resistance: a harmful relationship. J Intern Med 274: 25-40, 2013. https://doi.org/10.1111/joim.12071

BOUITBIR J, SANVEE GM, PANAJATOVIC MV, SINGH F, KRAHENBUHL S: Mechanisms of statin-associated skeletal muscle-associated symptoms. Pharmacol Res 154: 104201, 2020. https://doi.org/10.1016/j.phrs.2019.03.010

CASUla M, MOZZANiCA F, SCOTTI L, TRAGNi E, PIRILlO A, CORRAO G, CATAPANO AL: Statin use and risk of new-onset diabetes: A meta-analysis of observational studies. Nutr Metab Cardiovasc Dis 27: 396-406, 2017. https://doi.org/10.1016/j.numecd.2017.03.001

DEVARAJ S, SINGH U, JIALAL I: Human C-reactive protein and the metabolic syndrome. Curr Opin Lipidol 20: 182-189, 2009. https://doi.org/10.1097/MOL.0b013e32832ac03e

Di COSTANZO A, ANGELICO R: Formulation strategies for enhancing the bioavailability of silymarin: The state of the art. Molecules 24: 2155, 2019. https://doi.org/10.3390/molecules24112155

EBERLE D, HEGARTY B, BOSSARD P, FERRE P, FOUFELLE F: SREBP transcription factors: master regulators of lipid homeostasis. Biochimie 86: 839-848, 2004. https://doi.org/10.1016/j.biochi.2004.09.018

EBRAHIMPOUR-KOUJAN S, GARGARI BP, MOBASSERI M, VALIZADEH H, ASGHARI-JAFARABADI M: Lower glycemic indices and lipid profile among type 2 diabetes mellitus patients who received novel dose of Silybum marianum (L.) Gaertn. (silymarin) extract supplement: A Triple-blinded randomized controlled clinical trial. Phytomedicine 44: 39-44, 2018. https://doi.org/10.1016/j.phymed.2018.03.050

GILLESSEN A, SCHMIDT HH: Silymarin as supportive treatment in liver diseases: A narrative review. Adv Ther 37: 1279-1301, 2020. https://doi.org/10.1007/s12325-020-01251-y

GU M, ZHAO P, HUANG J, ZHAO Y, WANG Y, LI Y, LI Y, FAN S, MA YM, TONG Q, YANG L, JI G, HUANG $\mathrm{C}$ : Silymarin ameliorates metabolic dysfunction associated with diet-induced obesity via activation of farnesyl X receptor. Front Pharmacol 7: 345, 2016. https://doi.org/10.3389/fphar.2016.00345

GUO Y, WANG S, WANG Y, ZHU T: Silymarin improved diet-induced liver damage and insulin resistance by decreasing inflammation in mice. Pharm Biol 54: 2995-3000, 2016. https://doi.org/10.1080/13880209.2016.1199042

JAVED S, KOHLI K, ALI M: Reassessing bioavailability of silymarin. Altern Med Rev 16: 239-249, 2011.

KAMISAKO T, OGAWA H: Effects of pravastatin and bezafibrate on biliary lipid excretion and hepatic expression of Abcg5 and Abcg8 in the rat. J Gastroenterol Hepatol 19: 879-883, 2004. https://doi.org/10.1111/j.1440-1746.2004.03377.x 
MACH F, RAY KK, WIKLUND O, CORSINI A, CATAPANO AL, BRUCKERT E, DE BACKER G, HEGELE RA, HOVINGH GK, JACOBSON TA, KRAUSS RM, LAUFS U, LEITER LA, MARZ W, NORDESTGAARD BG, RAAL FJ, RODEN M, SANTOS RD, STEIN EA, STROES ES, ET AL.: Adverse effects of statin therapy: perception vs. the evidence - focus on glucose homeostasis, cognitive, renal and hepatic function, haemorrhagic stroke and cataract. Eur Heart J 39: 2526-2539, 2018. https://doi.org/10.1093/eurheartj/ehy182

MALINSKA H, ŠKOP V, TRNOVSKA J, MARKOVA I, SVOBODA P, KAZDOVA L, HALUZIK M: Metformin attenuates myocardium dicarbonyl stress induced by chronic hypertriglyceridemia. Physiol Res 67: 181-189, 2018. https://doi.org/10.33549/physiolres. 933606

MALINSKA H, OLIYARNYK O, HUBOVA M, ZIDEK V, LANDA V, SIMAKOVA M, MLEJNEK P, KAZDOVA L, KURTZ TW, PRAVENEC M: Increased liver oxidative stress and altered PUFA metabolism precede development of non-alcoholic steatohepatitis in SREBP-1a transgenic spontaneously hypertensive rats with genetic predisposition to hepatic steatosis. Mol Cell Biochem 335: 119-125, 2010. https://doi.org/10.1007/s11010-009-0248-5

MIHOS CG, PINEDA AM, SANTANA O: Cardiovascular effects of statins, beyond lipid-lowering properties. Pharmacol Res 88: 12-19, 2014. https://doi.org/10.1016/j.phrs.2014.02.009

NEHA, JAGGI AS, SINGH N: Silymarin and its role in chronic diseases. Adv Exp Med Biol 929: 25-44, 2016. https://doi.org/10.1007/978-3-319-41342-6_2

PORUBA M, KAZDOVA L, OLIYARNYK O, MALINSKA H, MATUSKOVA Z, TOZZI DI ANGELO I, SKOP V, VECERA R: Improvement bioavailability of silymarin ameliorates severe dyslipidemia associated with metabolic syndrome. Xenobiotica 45: 751-756, 2015a. https://doi.org/10.3109/00498254.2015.1010633

PORUBA M, MATUSKOVA Z, KAZDOVA L, OLIYARNYK O, MALINSKA H, TOZZI DI ANGELO I, VECERA R: Positive effects of different drug forms of silybin in the treatment of metabolic syndrome. Physiol Res 64 (Suppl 4): S507-S512, 2015b. https://doi.org/10.33549/physiolres.933235

PORUBA M, ANZENBACHER P, RACOVA Z, OLIYARNYK O, HUTTL M, MALINSKA H, MARKOVA I, GURSKA S, KAZDOVA L, VECERA R: The effect of combined diet containing n-3 polyunsaturated fatty acids and silymarin on metabolic syndrome in rats. Physiol Res 68 (Suppl 1): S39-S50, 2019. https://doi.org/10.33549/physiolres.934322

QI N, KAZDOVA L, ZIDEK V, LANDA V, KREN V, PERSHADSINGH HA, LEZIN ES, ABUMRAD NA, PRAVENEC M, KURTZ TW: Pharmacogenetic evidence that CD36 is a key determinant of the metabolic effects of pioglitazone. J Biol Chem 277: 48501-48507, 2002. https://doi.org/10.1074/jbc.M206655200

REHMAN K, AKASH MSH, LIAQAT A, KAMAL S, QADIR MI, RASUL A: Role of interleukin-6 in development of insulin resistance and type 2 diabetes mellitus. Crit Rev Eukaryot Gene Expr 27: 229-236, 2017. https://doi.org/10.1615/CritRevEukaryotGeneExpr.2017019712

SALAMI JA, WARRAICH H, VALERO-ELIZONDO J, SPATZ ES, DESAI NR, RANA JS, VIRANI SS, BLANKSTEIN R, KHERA A, BLAHA MJ, BLUMENTHAL RS, LLOYD-JONES D, NASIR K: National Trends in Statin Use and Expenditures in the US Adult Population From 2002 to 2013: Insights From the Medical Expenditure Panel Survey. JAMA Cardiol 2: 56-65, 2017. https://doi.org/10.1001/jamacardio.2016.4700

SATTAR N, PREISS D, MURRAY HM, WELSH P, BUCKLEY BM, DE CRAEN AJ, SESHASAI SR, MCMURRAY JJ, FREEMAN DJ, JUKEMA JW, MACFARLANE PW, PACKARD CJ, STOTT DJ, WESTENDORP RG, SHEPHERD J, DAVIS BR, PRESSEL SL, MARCHIOLI R, MARFISI RM, MAGGIONI AP, ET AL.: Statins and risk of incident diabetes: a collaborative meta-analysis of randomised statin trials. Lancet 375: 735-742, 2010. https://doi.org/10.1016/S0140-6736(09)61965-6

SILVERMAN MG, FERENCE BA, IM K, WIVIOTT SD, GIUGLIANO RP, GRUNDY SM, BRAUNWALD E, SABATINE MS: Association between lowering LDL-C and cardiovascular risk reduction among different therapeutic interventions: A systematic review and meta-analysis. JAMA 316: 1289-1297, 2016. https://doi.org/10.1001/jama.2016.13985

SKOTTOVA N, KAZDOVA L, OLIYARNYK O, VECERA R, SOBOLOVA L, ULRICHOVA J: Phenolics-rich extracts from Silybum marianum and Prunella vulgaris reduce a high-sucrose diet induced oxidative stress in hereditary hypertriglyceridemic rats. Pharmacol Res 50: 123-130, 2004. https://doi.org/10.1016/j.phrs.2003.12.013

SOBOLOVA L, SKOTTOVA N, VECERA R, URBANEK K: Effect of silymarin and its polyphenolic fraction on cholesterol absorption in rats. Pharmacol Res 53: 104-112, 2006. https://doi.org/10.1016/j.phrs.2005.09.004 
STEFAN N, MACHANN J, SCHICK F, CLAUSSEN CD, THAMER C, FRITSCHE A, HARING HU: New imaging techniques of fat, muscle and liver within the context of determining insulin sensitivity. Horm Res 64 (Suppl 3): 38-44, 2005. https://doi.org/10.1159/000089316

SURAI PF: Silymarin as a natural antioxidant: An overview of the current evidence and perspectives. Antioxidants (Basel) 4: 204-247, 2015. https://doi.org/10.3390/antiox4010204

TANGVARASITTICHAI S: Oxidative stress, insulin resistance, dyslipidemia and type 2 diabetes mellitus. World J Diabetes 6: 456-480, 2015. https://doi.org/10.4239/wjd.v6.i3.456

VAN ROOYEN DM, FARRELL GC: SREBP-2: a link between insulin resistance, hepatic cholesterol, and inflammation in NASH. J Gastroenterol Hepatol 26: 789-792, 2011. https://doi.org/10.1111/j.1440-1746.2011.06704.x

VELUSSI M, CERNIGOI AM, DE MONTE A, DAPAS F, CAFFAU C, ZILLI M: Long-term (12 months) treatment with an anti-oxidant drug (silymarin) is effective on hyperinsulinemia, exogenous insulin need and malondialdehyde levels in cirrhotic diabetic patients. J Hepatol 26: 871-879, 1997. https://doi.org/10.1016/S0168-8278(97)80255-3

VRANA A, KAZDOVA L: The hereditary hypertriglyceridemic nonobese rat: an experimental model of human hypertriglyceridemia. Transplant Proc 22: 2579, 1990.

WARD NC, WATTS GF, ECKEL RH: Statin toxicity. Circ Res 124: 328-350, 2019. https://doi.org/10.1161/CIRCRESAHA.118.312782

YU ZW, LI D, LING WH, JIN TR: Role of nuclear factor (erythroid-derived 2)-like 2 in metabolic homeostasis and insulin action: A novel opportunity for diabetes treatment? World J Diabetes 3: 19-28, 2012. https://doi.org/10.4239/wjd.v3.i1.19

ZICHA J, PECHANOVA O, CACANYIOVA S, CEBOVA M, KRISTEK F, TOROK J, SIMKO F, DOBESOVA Z, KUNES J: Hereditary hypertriglyceridemic rat: a suitable model of cardiovascular disease and metabolic syndrome? Physiol Res 55 (Suppl 1): S49-S63, 2006. 